\title{
Carnosic Acid and its Derivatives: Diterpenes of Biological Interest
}

\author{
Mariana Macías Alonso*, Sandra Rodríguez Sancén and Joaquín G Marrero* \\ Instituto Politécnico Nacional, México \\ *Corresponding author: Mariana Macías Alonso, Instituto Politécnico Nacional, México \\ Joaquín G Marrero, Instituto Politécnico Nacional, México
}

\begin{abstract}
ARTICLE INFO
Received: 幽 March 26, 2019

Published: April 01, 2019

Citation: Mariana Macías Alonso, Sandra Rodríguez Sancén, Joaquín G Marre-

ABSTRACT

Carnosic acid and its oxidized derivatives are phenolic abietane diterpenes found abundantly within members of the botanical family Lamiaceae, such as Salvia and Rosmarinus. Related scientific literature indicates these compounds have numerous bioactive properties. In this review, we present an overview of significant advances described in the latest literature concerning therapeutic applications of carnosic acid and its derivatives.
\end{abstract} ro. Carnosic Acid and its Derivatives: Diterpenes of Biological Interest. Biomed J Sci \& Tech Res 16(4)-2019. BJSTR. MS.ID.002877.
Keywords: Carnosic Acid; Carnosol; Cancer; Rheumatoid Arthritis; Biological Activities

\section{Mini-Review}

Carnosic Acid (CA) and its major oxidized derivative, carnosol, are phenolic abietane diterpenes present in various species of the Lamiaceae family, such as Salvia and Rosmarinus. The unstable nature of the carnosic acid molecule tends to oxidize easily and produce derivatives such as carnosol, rosmanol and isorosmanol [1]. For this reason, CA concentrations vary greatly in medicinal plants throughout the year. The highest amounts of CA are found during winter, probably due to higher precipitations, while their concentration is lower in summer [2]. The most common procedure to obtain these compounds is through isolation from the natural source [3]. However, several synthetic routes have been published. Tada et al. [4] have described a semi-synthetic process to obtain CA and carnosol from natural pisiferic acid, and some minor diterpenes such as rosmanol and 7-methoxyrosmanol have been efficiently obtained from carnosic acid [5]. CA and related diterpenes exhibit a wide variety of interesting biological properties, which have awaken interest within the medical and pharmacological communities. Diverse studies have demonstrated its antibacterial, antioxidant, antidiabetic, antitumor, leishmanicidal, and antiplasmodial properties, as well as neuroprotective and inhibitory effects for Human Immunodeficiency Virus (HIV) infection [6,7]. The anticancer activity of these compounds is of special interest given the significant increase in the number of cancer patients because of aging and growth of world population.

CA related compounds have shown these effects both in vitro and in vivo, including the inhibition of angiogenesis, proliferation and cancerous cells migration [8]. Rosmanol induced apoptosis in COLO 205 human colorectal adenocarcinoma cells with an $\mathrm{IC}_{50}=42 \mu \mathrm{M}$ [9]. Carnosol, on the other hand, inhibits breast and prostate cancers by binding to estrogenic and androgenic receptors respectively [10,11]. Additionally, several studies on CA prove its ability to cooperate with and enhance the effects of some drugs like tamoxifen [12] and trastuzumab [13], inhibiting breast cancer progression and increasing the sensitivity of glioma cancer cells to temozolomide [14]. Carnosol protects skin cells from Ultraviolet B radiation and inhibits melanoma growth [15], while CA improves the anticancer effects of carmustine and lomustine in melanoma, both in vitro and in vivo [16,17]. Rheumatoid Arthritis (RA) is a systemic autoimmune disease, characterized mainly by chronic inflammation of the joints, which is associated with progressive disability and premature death. CA and carnosol display significant in vivo dose-dependent anti-inflammatory and anti-nociceptive effects [18]. Xia et al. [19] demonstrated that the administration of $\mathrm{CA}$ to $\mathrm{db} / \mathrm{db}$ mice reduced the risk of systemic 
inflammatory condition through the suppression of the production of pro-inflammatory cytokines [20]. In a recent study conducted by Ishitobi et al. [21], CA demonstrated its potential as an agent for osteoarthritis prevention as well, reducing cartilage degeneration in articular chondrocytes through upregulation of hemeoxygenase-1.

It is estimated that the number of people living with Alzheimer's Disease (AD) will triple by year 2050. AD has been characterized by the accumulation of extracellular amyloid- $\beta$ plaques in an early stage followed by the formation of intracellular neurofibrillary tangled inclusions [22]. The ingestion of CA (30 mg kg-1 $\left.\mathrm{d}^{-1}\right)$ daily for 7 weeks can inhibit the intracellular oligomerization of exogenous $\mathrm{A} \beta 42 / 43$ monomer in C57BL/6 mice, which may have potential in the prevention of $A \beta$-involved diseases, particularly Alzheimer's disease [23]. On the other hand, CA inhibits triglyceride accumulation in ob/ob mice [24]. Zhao et al. [25] demonstrated that CA could dose-dependently ameliorate obesity and metabolic syndrome induced by a high-fat diet in C57BL/6J mice. The mechanism of action is simple, the inflammation and lipogenesis is supressed through Myristoylated Alanine-Rich C-Kinase Substrate (MARCKS) regulation [26]. In the present review, emphasis is placed on the therapeutic applications of CA and its oxidized derivatives. We believe that the information compiled in this minireview article will update scientists with recent findings on the biological activities of phenolic abietane diterpenes and help them improve their available information for further studies. Future goals in this field of research include the development of efficient methods to isolate these natural compounds and new synthesis strategies. Furthermore, it is essential to perform bioavailability studies and begin targeted clinical studies.

\section{References}

1. Masuda T, Inaba Y, Takeda Y (2001) Antioxidant mechanism of carnosic acid: Structural identification of two oxidation products. J Agric Food Chem 49: 5560-5565.

2. Luis JC, Johnson CB (2005) Seasonal variations of rosmarinic and carnosic acids in rosemary extracts. Analysis of their in vitro antiradical activity. Span J Agric Res 3: 106-112.

3. Grace MH, Qiang Y, Sang S, Lila MA (2017) One-step isolation of carnosic acid and carnosol from rosemary by centrifugal partition chromatography. J Sep Sci 40: 1057-1062.

4. Tada M, Ohkanda T, Kurabe J (2010) Syntheses of carnosic acid and carnosol, anti-oxidants in rosemary, from pisiferic acid, the major constituent of Sawara. Chem Pharm Bull 58: 27-29.

5. Marrero JG, Andrés LS, Luis JG (2002) Semisynthesis of rosmanol and its derivatives. Easy access to abietatriene diterpenes isolated from the genus Salvia with biological activity. J Nat Prod 65: 986-989.

6. Marrero JG, Moujir L, Andrés LS, Montaño NP, Araujo L, et al. (2009) Semi synthesis and biological evaluation of abietane-type diterpenes Revision of the structure of rosmaquinone. J Nat Prod 72: 1385-1389.

7. Bahri S, Jameleddine S, Shlyonsky V (2016) Relevance of carnosic acid to the treatment of several health disorders: Molecular targets and mechanisms. Biomed Pharmacother 84: 569-582.

8. López Jiménez A, García Caballero M, Medina MÁ, Quesada AR (2013) Anti-angiogenic properties of carnosol and carnosic acid, two major dietary compounds from rosemary. Eur J Nutr 52: 85-95.
9. Cheng AC, Lee MF, Tsai ML, Lai CS, Lee JH, et al. (2011) Rosmanol potently induces apoptosis through both the mitochondrial apoptotic pathway and death receptor pathway in human colon adenocarcinoma COLO 205 cells. Food Chem Toxicol 49: 485-493.

10. Petiwala SM, Puthenveetil AG, Johnson JJ (2013) Polyphenols from the Mediterranean herb rosemary (Rosmarinus officinalis) for prostate cancer. Front pharmacol 4: 29.

11. Johnson JJ, Syed DN, Suh Y, Heren CR, Saleem M, et al. (2010) Disruption of androgen and estrogen receptor activity in prostate cancer by a novel dietary diterpene carnosol: Implications for chemoprevention. Cancer Prev Res 3: 1112-1123.

12. Han NN, Zhou Q, Huang Q, Liu KJ (2017) Carnosic acid cooperates with tamoxifen to induce apoptosis associated with Caspase- 3 activation in breast cancer cells in vitro and in vivo. Biomed Pharmacother 89: 827837.

13. D’Alesio C, Bellese G, Gagliani MC, Aiello C, Grasselli E, et al. (2017) Cooperative antitumor activities of carnosic acid and Trastuzumab in ERBB2+ breast cancer cells. J Exp Clin Cancer Res 36: 154.

14. Shao N, Mao J, Xue L, Wang R, Zhi F, et al. (2019) Carnosic acid potentiates the anticancer effect of temozolomide by inducing apoptosis and autophagy in glioma. J Neurooncol 141: 277-288.

15. Tong L, Wu S (2018) The mechanisms of carnosol in chemoprevention of Ultraviolet B-light-induced non-melanoma skin cancer formation. Sci Rep 8: 3574.

16. Lin KI, Lin CC, Kuo SM, Lai JC, Wang YQ, et al. (2018) Carnosic acid impedes cell growth and enhances anticancer effects of carmustine and lomustine in melanoma. Biosci Rep 38: BSR20180005.

17. Baños MA, Olivares DAA, Olmos E, Saura MA, Castillo J (2013) Carnosol, radiation and melanomaa translational possibility. Clin Transl Oncol 15: 712-719.

18. Maione F, Cantone V, Pace S, Chini MG, Bisio A, et al. (2017) Antiinflammatory and analgesic activity of carnosol and carnosic acid in vivo and in vitro and in silico analysis of their target interactions. Br J Pharmacol 174: 1497-1508

19. Xia G, Wang X, Sun H, Qin Y, Fu M (2017) Carnosic Acid (CA) attenuates collagen-induced arthritis in $\mathrm{db} / \mathrm{db}$ mice via inflammation suppression by regulating ROS-dependent p38 pathway. Free Radic Biol Med 108: 418-432.

20. Liu M, Zhou X, Zhou L, Liu Z, Yuan J, et al. (2018) Carnosic acid inhibits inflammation response and joint destruction on osteoclasts, fibroblastlike synoviocytes, and collagen-induced arthritis rats. J Cell Physiol 233: 6291-6303.

21. Ishitobi H, Sanada Y, Kato Y, Ikuta Y, Shibata S, et al. (2018) Carnosic acid attenuates cartilage degeneration through induction of hemeoxygenase- 1 in human articular chondrocytes. Eur J Pharmacol 830: 1-8.

22. He Z, Guo JL, McBride JD, Narasimhan S, Kim H, et al. (2018) Amyloid- $\beta$ plaques enhance Alzheimer's brain tau-seeded pathologies by facilitating neuritic plaque tau aggregation. Nat Med 24: 29-38.

23. Meng P, Yoshida H, Tanji K, Matsumiya T, Xing F, et al. (2015) Carnosic acid attenuates apoptosis induced by amyloid- $\beta$ 1-42 or 1-43 in SH-SY5Y human neuroblastoma cells. Neurosci Res 94: 1-9.

24. Wang T, Takikawa Y, Satoh T, Yoshioka Y, Kosaka K, et al. (2011) Carnosic acid prevents obesity and hepatic steatosis in ob/ob mice. Hepatol Res 41: 87-92.

25. Zhao Y, Sedighi R, Wang P, Chen H, Zhu Y, et al. (2015) Carnosic acid as a major bioactive component in rosemary extract ameliorates highfat-diet-induced obesity and metabolic syndrome in mice. J Agric Food Chem 63: 4843-4852.

26. Song H, Li X, Liu Y, Lu W, Cui Z, et al. (2018) Carnosic acid protects mice from high-fat diet-induced NAFLD by regulating MARCKS. Int J Mol Med 42: 193-207. 
ISSN: 2574-1241

DOI: 10.26717/BJSTR.2019.16.002877

Mariana Macías A, Joaquín G M. Biomed J Sci \& Tech Res

(C) This work is licensed under Creative

Submission Link: https://biomedres.us/submit-manuscript.php

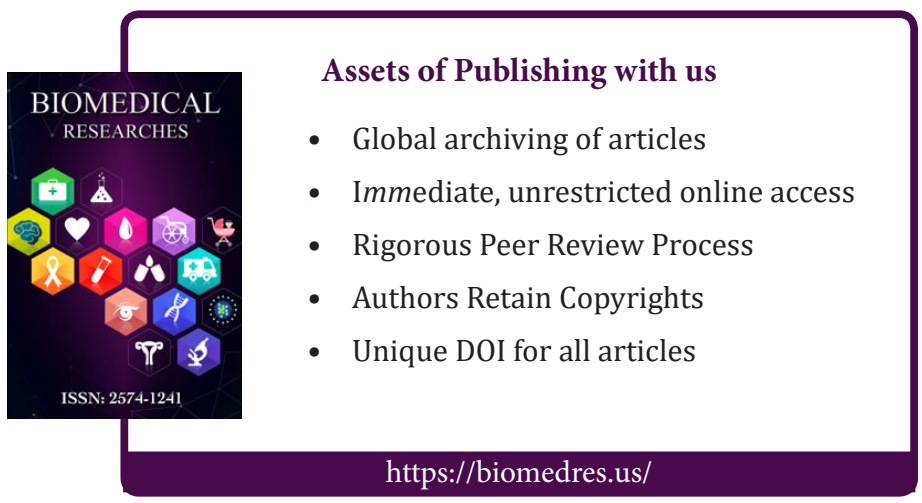

